\title{
The Logic of Decision Making in Engineering Design: An Examination of De- sign Theories From A Logical Point of View
}

\section{Dr. Soheil Fatehiboroujeni, Indiana-Purdue University}

Soheil FatehiBoroujeni received his Ph.D. in Mechanical Engineering from the University of California, Merced in 2018. As a postdoctoral researcher at Purdue University, School of Engineering Education, Soheil is working on a multi-institutional project characterizing governance processes related to change in engineering education, and pursuing other research interests in epistemology and design, among other philosophical topics in engineering education.

\section{Dr. Donna M. Riley, Purdue University-Main Campus, West Lafayette (College of Engineering)}

Donna Riley is Kamyar Haghighi Head of the School of Engineering Education and Professor of Engineering Education at Purdue University. 


\title{
The Logic of Decision Making In Engineering Design: An Examination of Design Theories From A Logical Point of View
}

\begin{abstract}
Designers rely on a variety of objects, practices, norms, and domain-specific knowledge when confronting the design tasks and undertaking their professional responsibilities. The responsibilities of individuals or groups (i.e., specific tasks at each stage of the design process) in their terminal phase, form a set of decisions that need to be negotiated horizontally, i.e., across teams, domains, and disciplines, as well as vertically, i.e., across hierarchical chains of authority that institute the design process. Therefore, a theory of justification and rationality of decision making in design has to account for the intersubjective or social nature of design. In negotiations, a diversity of constraints, commitments, and priorities clash, yet resolutions are found by some type of justification or rationalization. Design researchers and methodologists have developed or adopted theories of rational decision making, all with an impetus to enhance the efficacy of this process. While in meta-theoretical debates in human sciences or philosophy, the notion of logic is itself examined and debated, the majority of design methodologies take the meaning of logic as a given foundation or self-evident core of truth, traceable to what is often called classical logic.

In this paper, a number of design methodologies are briefly reviewed and three categories are introduced based on the logical commitments of methodologies. The first category entails methods such as rational choice theory that first developed within the discipline of economics and are built upon ternary axioms of classical logic. The second type of methods which have found application in the world of design to a lesser extent are built upon probabilistic or multi-valued logic. And finally, the third category encompasses theories of decision making built upon a dialectic interpretation of logic which we propose as a viable alternative for engineering design. decision making in the literature of social and political sciences has been continuously a focus of scholarly attention. Models and frameworks in this space often take into account the complex socio-political context of decision making and ensuing strategic action. We discuss the elemental role of epistemology and ontology in both theory and practice of design considering the socio-historical character of rationality, negotiations, and justification in engineering. In addition, we present how formal disputations as the most prominent instance of dialectic processes can provide a framework to map the reasoning and thinking in design by using a preliminary data analysis.
\end{abstract}

Keywords: logic of design, decision making, design philosophy 


\section{Introduction}

Design and engineering of technological artifacts are the core functions of modern corporations that are situated in an increasingly international network of production, distribution, and exchange. It is well established in Science and Technology Studies (STS) ${ }^{1}$ or history and philosophy of technology $y^{233}$ that social and political intentions as well as technical and instrumental necessities determine the outcome of design and engineering decisions. Industrial and technological corporations are establishments with financial, political, and moral roadmaps that among other entities such as research universities, national labs, or government agencies constitute an ecology of knowledge $e^{4}$. Contemporary and historical accounts of this ecosystem demonstrate how rearrangements in the national priorities, aspirations, and changes in domestic or international landscape of politics and economics contribute to the evolution and production of knowledge. Therefore, in design research a fundamental epistemological question is the relationship between the individual and the social levels of analysis. Do the individual factors such as cognitive models used by designers explain the phenomenon in question, or do the social factors such as institutional and legal frameworks, and more importantly historically accumulated forms of cultural and material capital buttress epistemic explanations of the individual actions?

Moreover, even if one confers the epistemic status of objectivity or observer-independency to the knowledge of technical and scientific disciplines, any application of these forms of knowledge for synthesis of technological artifacts involves perspective taking, boundary drawing, and premeditated human action, therefore problematically subjective, i.e., conditioned by observer-dependent factors such as (tentative) judgements, calculations of interests, and even individual or group sensibilities. With design, one intends to change the world (or parts of it) and changing the world or working for the betterment of any state of affairs, presupposes an interpretation or a conception of the world. The world can not be designed from without, but from within. Here, we are interested in engaging with the theoretical implications of such a self-reflexive process. This paper seeks to analyze how design researchers resolve the relationship between objective contexts and structures, versus the subjective agency and intentionality of designers.

The basic and long-standing questions we touched upon in that past two paragraphs-first the relationship between the individual and the social direction of explanations, and second the relationship between the structure and agency-are at once epistemological and ontological. Any inquiry seeking to systematize or resolve these questions would entail knowledge claims (interpretations and/or explanations) on the characteristics and constitution (nature) of engineering design. This paper is an effort to demonstrate how a logical point of view, i.e., examining how inquiries in design research figure the notion of logic, can make effective inroads in addressing aforementioned questions.

Design researchers and methodologists have developed or adopted various theories of rationality in engineering decision making, all with an impetus to enhance the efficacy of this process and often to bring to light the essence of design. In this paper, a number of design methodologies are briefly reviewed and three distinct categories are introduced based on their logical commitments. The first category entails methods such as rational choice theory that first developed within the discipline of economics and are built upon ternary axioms of classical logic. The second type of methods which are yet less applied in the world of design are built upon probabilistic or multi- 
valued logic. And finally, the third category encompasses theories of decision making built upon a dialectic interpretation of logic which we propose as an alternative. decision making in the literature of social and political sciences have been continuously a focus of scholarly attention. Models and frameworks in this space often take into account the complex socio-political context of decision making and ensuing strategic action. We discuss the elemental role of epistemology and ontology in both theory and practice of design to better make explicit the socio-historical character of rationality or justification in engineering. In addition, we present how formal disputations as the most prominent instance of dialectic processes ${ }^{5}$ can provide a viable framework for mapping the reasoning and thinking in design.

\section{Logic of Design}

In western philosophical tradition logic is concerned with examining the structure of valid inferences. For example, a syllogism, or a deductive argument each have a unique underlying logical form or structure. Form in this context refers to the relationship between context-independent logical terms such as and, or, if and context-dependent terms such as woman, gene, machine ${ }^{6}$. A logically true inference, in this tradition, is true by virtue of its form regardless of the content. Logical forms, hence, are relational patterns of locutions (verbal elements) in statements. Logic, thus construed, is the science of necessary thinking ${ }^{7}$ or necessary inferences ${ }^{6}$.

Ever since the inception of this tradition, several problems have arisen as the framework has expanded. Examples include inferences regarding time (past, present, future) or events influenced by human action (e.g., a battle or a contest) that create a theoretical impasse, commonly known as the "problem of future contingents". Another long-standing, consequential, and actively researched problem is that of semantics, i.e. the relationship between the meaningful and true statements and the reality to which statements refer. In this section, without delving deep into the science and philosophy of logic, we briefly review how design methodologies can be categorized by three distinct conceptions of logic. In so doing we also intend to portray some of the common narratives on rationality of engineering and design.

\subsection{Classical logic}

The first category of design methodologies are those committed to three axioms of classical logic, namely,

a. the law of identity which states everything is identical to itself,

b. the law of contradiction (or non-contradiction) which states that contradictions are not acceptable,

c. and the law of excluded middle which states if a proposition is not true its negation must be true.

In the following we first review two major developments in this domain. First, we present a widely received model of synthesis (or production) in design thinking. Second, we examine how a focus 


\section{Inference}

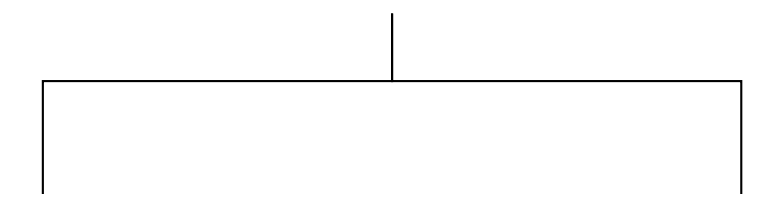

\section{Analytic}<smiles>C=CC</smiles>

\section{Deductive}

- Rule: $x \leq y$

- Case: $y \leq z$

$\therefore$ Results: $x \leq z$

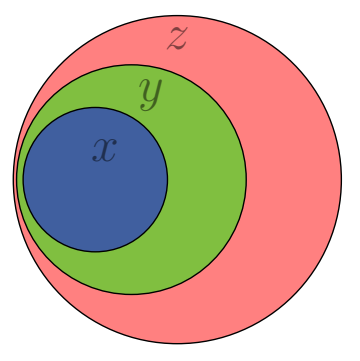

\section{Synthetic}

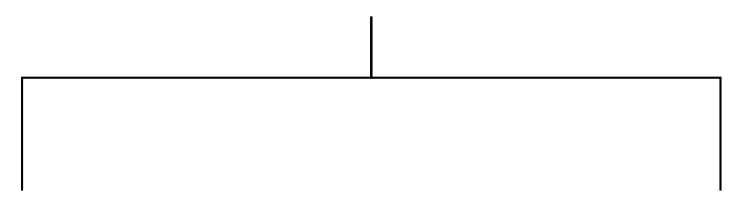

Inductive

- Case: $\quad x \leq y$

- Results: $x \leq z$

$\therefore$ Rule: $y \leq z$
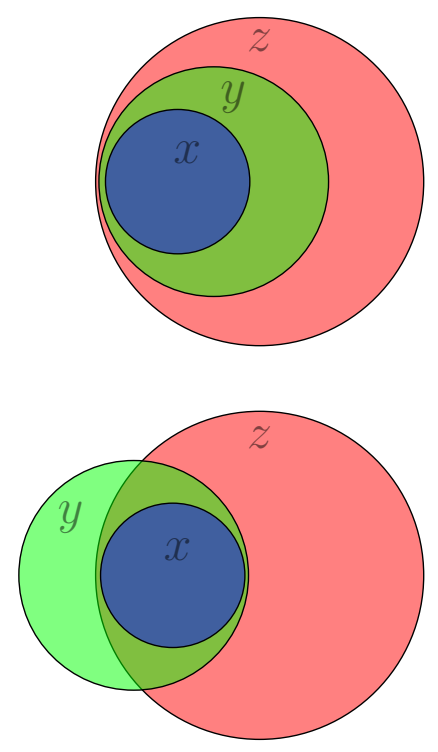

\section{Abductive}

- Rule: $y \leq z$

- Results: $x \leq z$

$\therefore$ Case: $x \leq y$
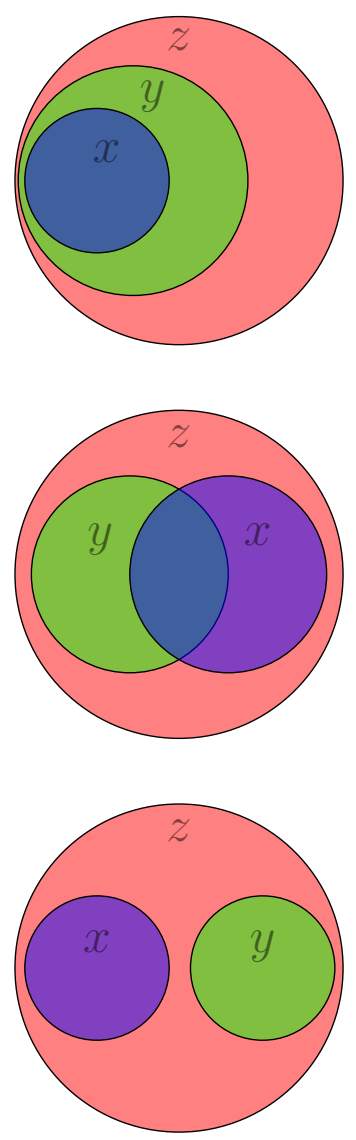

Figure 1: Peirce's classification of logical inferences. In deduction, by knowledge of the rule, $x \leq y$, for all cases where $y \leq z$, we can infer that $x \leq z$ necessarily. In induction, we infer the rule, $y \leq z$ on the basis of observing the result that a subset of $y$, which is $x \leq y$, belongs to $z$, i.e., $x \leq z$. Hence, there is always a non-zero possibility that unobserved members of $y$ not belonging to $z$ which is a contradiction to the rule inferred. In abduction, by observing the result, $x \leq z$ and knowing the rule, $y \leq z$ we hypothesize (abduct) the case that $x \leq y$ which, similar to induction, is not a logical necessity. 


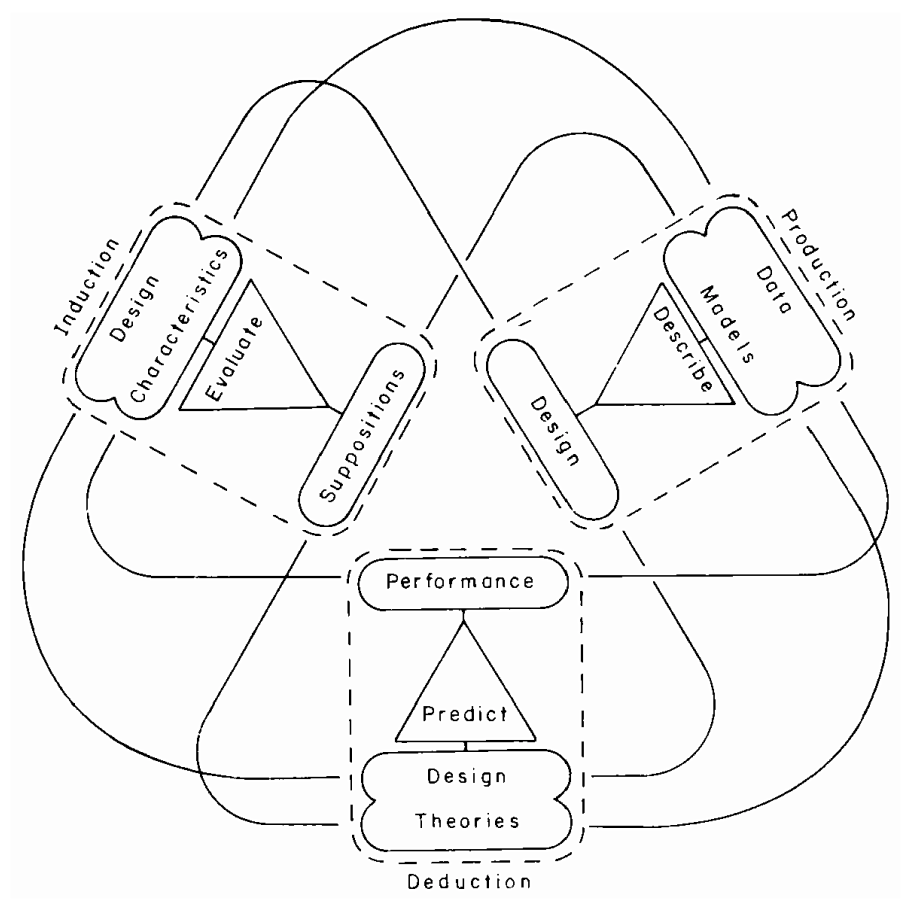

Figure 2: March's representation of design logic as an iterative process of production (abudction), deduction, and induction 10 . The scheme does not identify a certain sequence, nor a definite beginning and end, nor a criteria for termination of the process. Figure used with author's permission.

on the notion of expected utility is resulted into mathematical axiomatizations adaptable for design reasoning and decision making. Our introduction and overview of each approach is fused with critique and evaluation.

\subsubsection{Logic of Production}

A pioneering and remarkable development in this category can be found in the works published by Lionel March ${ }^{8}$ who adopted Peirce's typology of inferences ${ }^{9}$ in building a deductive-inductiveabductive logic of design. As shown in Figure 1, Peirce delineates two basic types of inferences, namely, analytic and synthetic. Deductive arguments are the sole constituent of analytic category. In deductive inferences, conclusions are approvable with absolute certainty because the premisses contain the conclusions-or alternatively, the subject itself contains the predicate. In a deductive inference (or analysis proper) the truth of statements is carried from the premisses to the conclusions.

Furthermore, Peirce ${ }^{9}$ introduces inductive and abductive inference as two species of synthetic (or productive) inferences. Induction, as shown in Figure 1, is inference of a rule that generalizes (extends) the results observed in a finite number of cases to unobserved cases. Therefore, from a logical point of view the truth of inductive conclusions are not warranted with certainty; any potential case that is yet to be observed could turn out to be an exception to the rule. Hence, induction is not a logically necessary inference. Given the inductive form of scientific laws and 
logical uncertainty of inductive thought, scientific logic, most explicitly after Hume, is faced time and again, with the problem of induction.

Abduction is the second type of productive inferences in which a case is hypothesized, given a set of results and commitment to (or knowledge of) a general rule. For example, if I know that all trees in my orchard are pear trees (the rule) and observe a pear on the ground in my orchard (result), I can abduct the case that this pear belongs to one of my trees. Alternatively, I could abduct the case that this pear was thrown here by a pear-carrying stranger infiltrating my yard, hence not belonging to any of my trees. Although both of these inferences have the same logical form, former appears as a more plausible option, but only in virtue of other circumstantial information we usually bring to bear on a case such as prior experiences where we have seen pears falling under the pear trees versus rarity of observing, or learning about fruit-carrying infiltrators in an orchard. Again, similar to induction, the truth of abductive conclusions are not warranted with certainty since multiple cases with a logical equivalence are capable of, as it were, bridging the observed result to the presupposed rules.

To summarize, in contrast to analytic inference, a synthetic inference does not ascertain the necessity or unconditional truth of the conclusions. However, the productive character of synthetic inferences-either in extending a rule or in abducting one hypothesis among many possible hypotheses-renders these constructs useful in both science and engineering as shown in the literature of design studies $\frac{11 / 12}{}$.

Figure 2 demonstrates March's graphical representation of reasoning in design as an iterative process between deduction, induction, and abduction. In the productive stage, a solution to the design problem is framed (a case), given the scientific models (rules) and data describing the constraints and specifications of the product (results). In the deductive mode, given the solution of previous step (a case, for example, a prototype or a tentative solution) and given scientific theories (rules) we can analytically predict the performance of the solution (results). And finally, in the inductive zone, we can infer suppositions (rules) based on the given solution (case) and its performance characteristics we observe (results). This process results in new knowledge about the design problem which can then be utilized in subsequent iterations.

This pioneering work on design logic gives a schema of the form and content of design thinking; it is empirically refinable and normatively flexible. For example, in Figure 2 note the lines connecting the blocks do not have directionality. Yet, it can be criticized from several standpoints. First, as an account of design rationality it is ambiguous or mute with respect to the problem of closure and decision making. The theory could be pressed for an answer as to what are the standards or criteria of terminating the iterative inferences into a final resolution? The severity of consequences, for example from a security point of view (safety or protection of lives or intelligence), or an ethical point of view (matters of rights, justice, or life and death) directly influence the criteria with which reasons are deemed sufficient or not, accepted or rejected. Reasoning in this model, seems to be equivalent to information processing along a certain path using the ternary modes of inferences. The institutional and socio-historical contexts in which design and engineering decision making are situated, the distribution of knowledge, information, and authority in the ecosystem of knowledgeare some of the missing elements in this model. As a paradigm for design research, such an interpretation of logic could result in a form of methodological individualism capable of generating explanations (of a social phenomenon) solely on the level of individual cognitive 
models.

\subsubsection{Rationality as Utility Maximization}

Another major development in the logically classical category is the application of rational choice theory in engineering design. Rational choice theory is an umbrella term encompassing models developed in mathematical game theory or neoclassical (mainstream) economics. The hegemonic dominance of neoclassical economic thought ${ }^{\frac{13 / 14}{16}}$ has been a major force in widespread application of this approach in social and political sciences, as well as design studies in engineering ${ }^{15}$. In rational choice theory scholars have developed mathematical models that quantify the preferences of an agent (or agents, in the case of game theory) vis-a-vis available alternatives. The purported goal is to produce an objective (observer-independent) science of decision making.

Rational choice theory, to be a descriptive (positive) science, develops a formal system (a formulation) that allows for deduction of testable predictions on the behavior of (economic) agents. Such formalization is possible only by postulating a set of axioms that anchor the chain of deductive inferences within the system. Deductions (or derivations) within a formal system allow for the truth of axioms to flow outward into the analytic system. Axioms are statements capturing fundamental truth claims about the object of study-the objective reality-hence, are in part ontological speculations not themselves directly testable. Axiomatization is the paradigmatic modus operandi of positives sciences. More importantly, objectification, i.e. posting the distinguishability and independence of objective versus subjective categories (observer-dependent concepts versus observer-independent reality) underpins all positivist axiomatizations. In the next section, we comment on how such demarcations are gravely problematic in the study of social and human phenomena.

To further clarify this approach we can look at the methodological axioms of rational choice theory 14 . Despite incessant developments and cross-disciplinary variations, the following axioms remain indispensable to rational choice theory:

a. methodological individualism

b. methodological instrumentalism

c. methodological equilibration

The first axiom, methodological individualism, is concerned with the agency, structures, and the relationship between the two. As mentioned earlier, the agency-structure relationship has been a long-standing meta-theoretical and philosophical challenge in human sciences $\frac{16}{16}$. Other sciences to the exclusion of cognitive and neural sciences have been able to avoid this challenge due to their focus on non-human parts of the world. Consider the following question. Is it the intentional acts or agency of individuals that shapes the social structures such as laws and institutions (of governance, or of marriage for example), or is it the environment and social conditions that determine the acts of an individual. In this problematic relationship, neither structuralism nor individualism seem to be able to bear the blows of critique. As we will elaborate more at a later point, structure and agency can be regarded interdependent and reciprocal, hence demanding theoretical reciprocity: explanations of the whole and the knowledge about the social structures can be synthesized into 
explanations of the individual behavior, and similarly, explanations of the parts and the knowledge about the individual, too, can be synthesized into explanations of the whole. The methodological individualism of rational choice theory falls short of attending to one of these two explanatory directions by positing that all explanations of the existing structures and intentionalities, are derived exclusively from explanations at the level of the individual.

The second axiom, methodological instrumentalism, gives the modeled individual (homo economicus) its sense of direction. Instrumental rationality posits that, the behavior of a rational individual is, or ought to be a function of his or her preferences. The preferences are alternatives or ends one seeks to achieve, ordered transitively, they determine the behavior and the chosen means. Therefore, instrumentalism is equivalent to consequentialist moral theory "in which the only consequence that matters is the extent to which a homogeneous index of preference-satisfaction is maximised"13. It leaves out phenomenon such as introspection, or moral beliefs that are endogenous sources of what one counts as self-interest.

Finally, the third axiom, methodological equilibration, presumes a multi-agent system is in equilibrium state. This is necessary to render the system of equations deterministic and solvable ignoring the empirical possibility of non-equilibrium or indeterminacy.

Rational choice theory is often labeled as scientific and rigorous. As a descriptive or positive science its empirical track record of predicting decision behaviors has been poor ${ }^{17}$ and many scholars today describe it as a normative (prescriptive) approach-a move that puts the enterprise in sharp contrast to other natural sciences. Although it accomplishes the task of mathematizing human rationality, along the way it requires simplifications and philosophical postulations that in certain cases render the theory irrelevant to empirical reality. Philosophical evaluation and revision of fundamental ontological assumptions (i.e., the grounding axioms of the theory) is a pathway to resolve or explain away the observations irreconcilable with theoretical predictions. Institutionalist approaches to economic theory and decision making ${ }^{18}$ have offered significant reconceptualization and correction to this paradigm, yet are not being applied to engineering contexts to the best of our knowledge.

\subsection{Probabilistic Logic}

Despite the dominanance of a classical interpretation of logic in design studies, there have been developments in using non-classical interpretations of logic ${ }^{19}$ to construct frameworks of inference with direct application in practical domains such as engineering design. Limitations caused by the bivalence principle (i.e., that truth-value of statements is a true-false binary) for example in scenarios where truth-values need to attain true, false, or indeterminate while conducting a threevalued logical calculus, has been a motivation, inter alia, to formalize multi-valued or probabilistic varieties of logic.

In this category we only mention one example which has a potential to offer an alternative perspective for reasoning and decision making in design. Consider having a set of goals, specifications, constraints, priorities (financial, ethical, aesthetic, etc.), and statements (or formulae) encoding designers' knowledge and degree of uncertainty. Next, suppose designers sketching and formulating 
a number design alternatives and seeking a systematic way to sort alternatives and to make decisions. Markov Logic Network (MLN) is designed to make inferences and quantitatively identify among all "possible worlds" the one that better matches the designers' priorities. A possible world is defined by a set of logically dependent statements, or a so-called knowledge base (KB).

"A first-order KB can be seen as a set of hard constraints on the set of possible worlds: if a world violates even one formula, it has zero probability. The basic idea in MLNs is to soften these constraints: when a world violates one formula in the $\mathrm{KB}$ it is less probable, but not impossible. The fewer formulas a world violates, the more probable it is. Each formula has an associated weight that reflects how strong a constraint it is: the higher the weight, the greater the difference in log probability between a world that satisfies the formula and one that does not, other things being equal."

Given a set of statements $(F)$ and a set of weights associated with them $(w)$ representing the importance of each constraint, Markov Logic Network could evaluate multiple design alternatives, or test multiple values for each priority. Such an approach, potentially allows engineering designers to systematically adopt a more inclusive and reflective attitude by being conscious of the normative, and subjective aspects of decision making. For example, suppose a scenario where formula number one, $F_{1}$ captures financial constraint, total cost $<\$ 10,000$ with a normalized weight of $w_{1}=1$, and formula number two, $F_{2}$ representing the rate of producing an environmental pollutant, total mass $<10,000 \mathrm{lb}$ with normalized weight $w_{2}=0.5$. Assessment of design alternatives using MLN can be done not only for this set of values-embodying a set of decisions and value-judgments on significance of each constraint-but also for a varying set of weights such as $w_{2}=0.8$ or $w_{2}=1$ representing, in effect, another set of decisions regarding design priorities. Nonetheless, similar to previous category, the method lacks explanatory power at multiple levels of analysis (the level of the individual in combination to the level of the ecosystem).

In the next section we introduce the third identifiable category of methods. By that, we also engage in a more detailed discussion of the shortcomings mentioned so far.

\subsection{Dialectic logic}

Depending upon the context, dialectic designates two different ideas. First, in argumentation theory or rhetoric ${ }^{20}$ it is construed as a method of thinking cogently and devoid of mistakes; here dialectic refers to the science as well as the art of reasoning. Alternatively, there is a historical chain, starting from Heraclitus and Plato, continuing to Hegel, and culminating in the Frankfurt School (i.e., Adorno, Horkheimer, et al) in which dialectic is construed more philosophically and radically. In the following, we briefly review the a segment of literature in both traditions.

\subsubsection{Dialectic as Intersubjective Reasoning}

In the world of design and decision making the first interpretation of dialectic is more often applied practically and pedagogically ${ }^{21 / 22 \mid 23}$. Nicolas Rescher ${ }^{[5}$ has developed a formal representation of 
Proponent Opponent

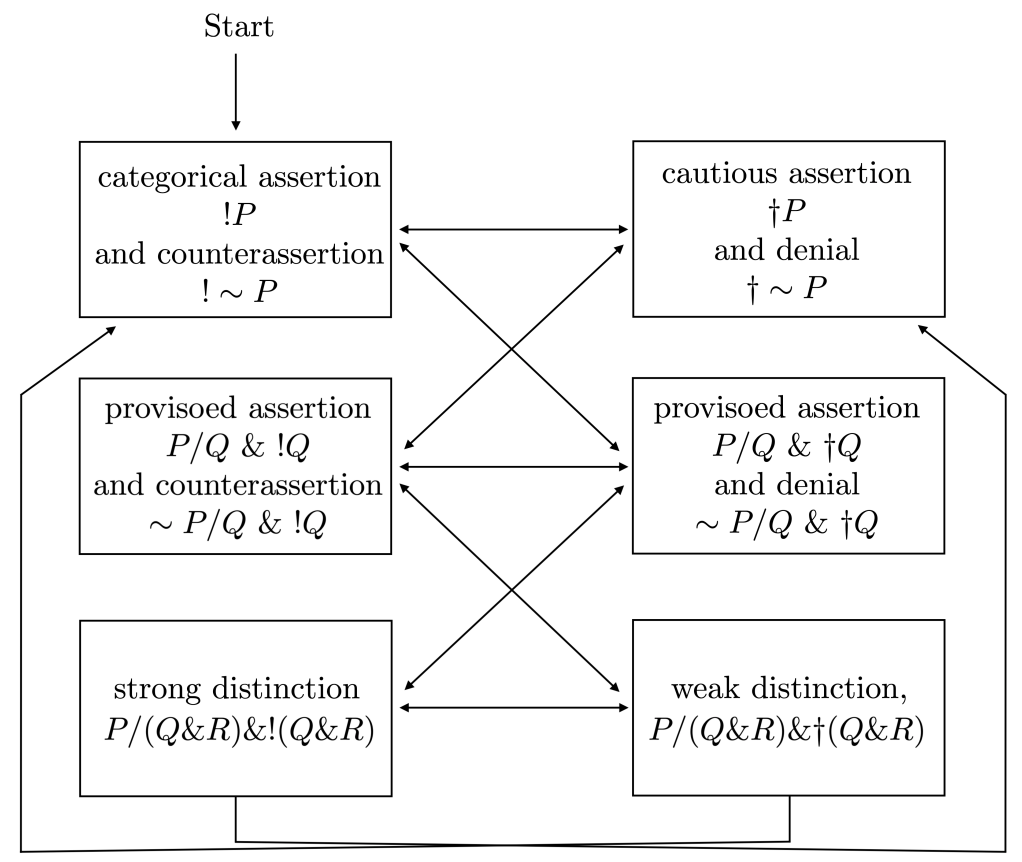

Figure 3: Rescher's formalism ${ }^{5}$ of rational disputations illustrates possible moves each party can hold onto as dialectic process evolves.

rational disputations which also he argues to be a veridical model of epistemic inquiry. Rescher's formalism of rational disputations, shown in Figure 3, sketches how justification and reasoning in an intersubjective inquiry evolves. In this view, dialectic has a probative origin; it is the process in which proponents of a thesis $(T)$ seek to specify grounds $\left(G_{i}\right)$ that respond to refutations of opponents $\left(R_{i j}\right)$. The inquiry is contingent on a set of shared presumptions (a cognitive status quo) as the foundation, as well as a set of criteria for plausibility and adequacy. The third actor in the process is determiner (individual or collective) concerned with termination or adjudication of the rational debate.

Figure 3 shows possible moves or types of arguments that each party can employ as the dialectic process evolves. Disputation begins with proponent claiming one of the fundamental moves. This could be either a categorical assertion $(! P)$ for " $P$ is the case" or a provisoed assertion $(P / Q \& ! Q)$ for " $P$ generally (or ordinarily) holds provided that $Q$, and for all we know $Q$ is the case". The opponent can respond to either with a cautious denial $(\dagger \sim P)$ for " $\sim P$ is the case for all that you have shown", or a provisoed denial $(\sim P / Q \& \dagger Q)$ for " $\sim P$ obtains in all (or most) ordinary circumstances when $Q$ does and for all we know $Q$ is the case".

Note that when a provisoed assertion is countered by a provisoed denial, symbol $P$ represents the same statement for both parties, while $Q$ indeed can not be the same. Consider the following excerpt form a group of mechanical engineering students at the earliest stage of planning for the design of a mechanism to handle hazardous explosive material. This data belongs to the Design Thinking Research Symposium ${ }^{24 \mid 25}$ (DTRS 2013) which deposits design review conversations by 
design learners in mechanical engineering, industrial engineering, choreography and a number of other disciplines.

“The electrical components aren't gonna be actually on the assembly because we don't want any component or batteries being near an explosion because that could cause it to be dangerous. So we're running off the actual mechanism so no electrical components will be actually on it. [...] it's gonna be a wire running off of it..."

In this case, the provisoed assertion can be summarized as follows.

$P$ : Electrical components or batteries will be in danger of loss.

$Q$ : Explosion occurs.

Therefore, the argument to justify the decision of housing the electronic parts off the main body of the device to prevent explosion or other dangerous consequences has the form, $(P / Q$ and $! Q)$. A hypothetical provisoed denial could be of the form $(\sim P / Q$ and $\dagger Q)$ where $P$ is the same statement and

$Q$ : With redundancy in motion constraints explosions are prevented.

Finally, another type of move in Rescher's formalism is strong distinction $(P /(Q \& R) \& !(Q \& R))$ by proponent, or a weak distinction $(P /(Q \& R) \& \dagger(Q \& R))$ by opponent. Distinctions are widely used to more clearly denote and delimit the circumstances in which a claim is valid. This system provides a first-order formalism of rational disputations.As an approach to structure the arguments and counterarguments Reschers's approach provides a methodologically strong tool that is immediately usable for empirical studies.

\subsubsection{Dialectic as Necessity of Development}

In contrast to the first interpretation of dialectic, the second interpretation amounts to a philosophical system that, among other things, seeks to resolve the relationship between thought and reality. Here, we draw on the literature from the first generation of the Frankfurt School, in particular Adorno's lectures on "An Introduction to Dialectic" 26 to develop the discussion. Our explanation revolves around the concept of necessity as it is intended, for example, by the notions such as the laws of nature within scientific disciplines or positivist tradition. Positive sciences rely on ontologically exclusive and independent categories such as objects and subjects, thoughts and reality. Note that we do not observe or experience any physical object, we have only access to the effects of objects in our sense-experiences. Positive sciences identify patterns observed in our sense-experience. However, to avoid solipsism, this is contingent upon the existence of objects with fixed essences, in addition to immutable laws as the determinant of events-to put it metaphorically, the locus of necessity is in the existence of natural laws describing the essence of objects existing beyond, and causing our sense-experiential observations. As epistemic enterprises positive sciences seek to produce a true knowledge or representation of the world using concepts that are built upon an essentialist philosophy. 
Dialectic, however, undermines all of the above. The only necessity, it claims, is the necessity of development or change. Next, it claims, there are no such things or categories as representations, thoughts, and concepts independent of reality. To unpack this, first note that a conception, i.e., determining what a concept means or refers to, is at the same time a determination on what the concept is not-a determination on the negation of that concept. Second, the relationship between concepts and objects is not governed by necessity or direct empirical tests. Such determinations are historical processes, and are only possible by adopting a specific interpretation of the world into a net of concepts; while some scientific concepts and categories are directly observable and grounded in facts, a scientific theory needs to bundle those concepts with other (ontological) posits and rules (e.g., space-time homogeneity, axioms of classical logic, etc.) which it imposes on the world or accepts as a matter of dogma. Science neither tests, nor devoids itself of metaphysical and ontological posits, but it becomes what it is (a fruitful method of objectification and pattern identification) precisely by so doing. Hence, no concept (no axiom) and no finite combination of them can represent ahistorical (i.e. natural) truths. To put it differently, concepts and thoughts are imposed on the world as much as they are derived from it. And finally, dialectic purports, true understanding of this tension between essentialism versus historicism is grasped by the negation of the negation: by rejecting to consider the first negation, i.e., historicism versus essentialism, as a logical paradox, and regarding it as a pair of necessary (dialectic) others, through which change can occur and stages of development manifest. Truth is a tenable notion in this system. It is attainable by the movement of thought. At their most purest, concepts or thoughts are ideas, development of which is towards the idea of pure being-the unity of subjects and objects-hence the name, Hegelian Idealism.

Although these last statements on truth are about the Idealist philosophy of Hegel, a materialist interpretation of dialectic philosophy is also developed and well established within the Marxist tradition which indeed has had a profound influence within certain disciplines such as social and political sciences. The reason for this influence is due to the wide inapplicability of scientific ontology-i.e., distinguishability and independence of thought and reality-in social life and human affairs. For example, ability of agents to model the economy (i.e., having meaningful information) is mediated by, if not conditional on, scientific concepts of economic theory and, at the same time, is a crucial element of the reality which a science of economy must model. We construct the economic reality after our theoretical dispositions, as much as the economic theory is built upon the reality. In brief, the unity of perception and reality is patently apprehensible in the systems and objects of study constituted by human beings.

Dialectic thinking seeks to grasp the developmental and relational linkages among concepts. It seeks to understand the developments resulting from the interactions within a system. As we hoped to convey in previous paragraphs, it is not anti-positivist, neither it is pro-positivist. It does not require to reject or refute classical logic, or any axiomatic formalism; any theory of that kind might pragmatically be viable, especially where objectification can enhance our knowledge of, and ability to control an objective domain using positive sciences. What this perspective implies, however, is to reject both essentialism and historicism as true interpretations of thought-reality relationship. The only measurable epistemic progress of positive sciences lies in their predictive capacity of the observable sense-experiences. The correspondence of theory and reality, i.e., the notion of truth as the accumulative correspondence of scientific concepts, postulates, and posits with an immutable and natural necessity existing above and beyond the concepts is neither what 


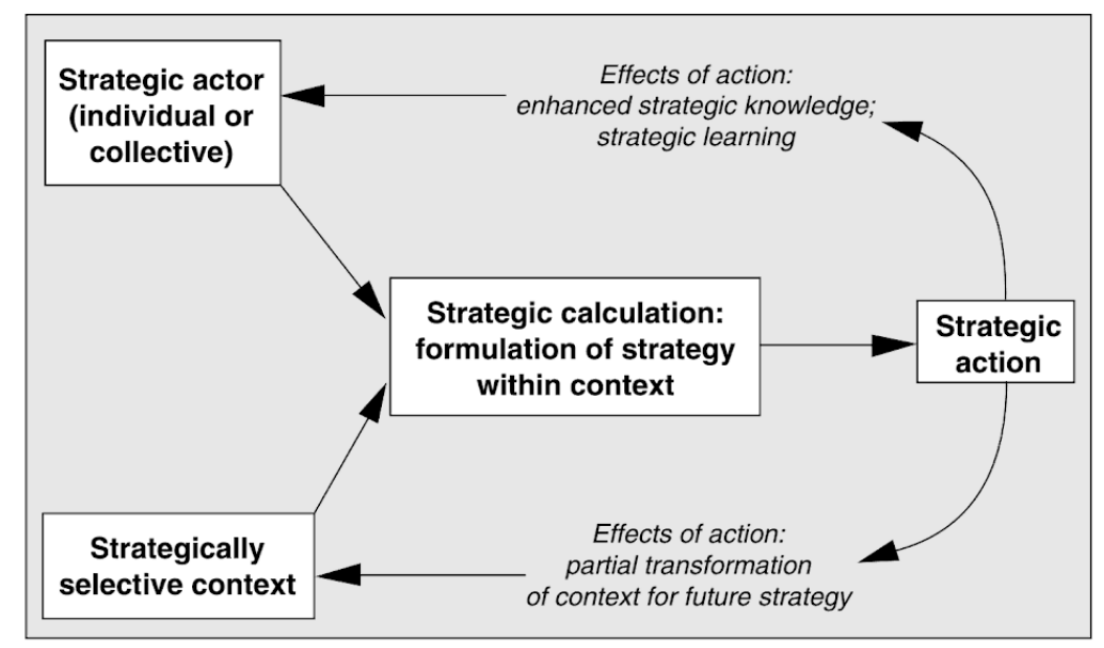

Source: Adapted from Hay (1995b: 202).

Figure 4: Graphical representation of decision making and action as the interaction of agency and structure by Colin Hay ${ }^{28}$. Figure used with author's permission.

is done, nor what is measured in science (or philosophy of science for that matter). Thus, the only remaining path to salvage the notion of truth seems to be a dialectic interpretation of the representation and reality; it is not to be encapsulated in any doctrin or theory. Truth is what we actually do and what we collectively and individually bring about in practice.

Now, we ask how philosophical dialectic relates to the science of decision making and engineering design. Our discussion is focused on the structure-agency problem $\frac{1627}{1}$ that, not coincidentally, is at the forefront of meta-theoretical research and debate on social, political, and economic theory. The problem can be figured as follows: What is the relationship between individual human actions, and the context, environment, or structures (e.g., institutions, discourses) pertaining to actions. Is it human agency or intentionality that shapes the structures and the context or is the reverse the case? A growing number of scholars, using dialectic logic, endorse a dual view. Marsh ${ }^{16}$ summarizes this view as follows:

- Structures provide the context within which agents act, but agents interpret structures, and, in acting, change them, with these 'new' structures becoming the context within which agents subsequently act.

- Similarly, material relations provide the context within which ideas develop and operate, but ideas are used to interpret those material relations and these interpretations help change those material relations. These 'new' material relations then become the context within which ideas develop."

The key here is to conceptualize structure and agency with reciprocity and interactively, instead of viewing the individual and society in distinctly separate categories. Despite the individualism of rational choice theory, the vector of constitution between individual and society here is two-way.

Figure 4 demonstrates the interplay of strategic action, structure, and agency in the context of po- 
litical science ${ }^{28}$ using a dialectic interpretation. This approach, we contend, gives a rich picture for understanding the nature of thinking and decision making in design. It is capable of conceptualizing the self-reflexivity of the phenomenon; design agents and institutions do not look at the object of their work from without, but from within. They are themselves part of that object which is a technological society. Moreover, this approach allows both designers and design scholars to flexibly engage with the task of explaining and understanding, from multiple levels of analysis ${ }^{29}$. This approach does not deny the role of individual breakthroughs, creativity, and authenticity that result in innovation and novel forms of activity. Nonetheless, the socio-historical ecosystem which individuals inhabit also plays a crucial role in determining how and why such innovations evolve into a technology.

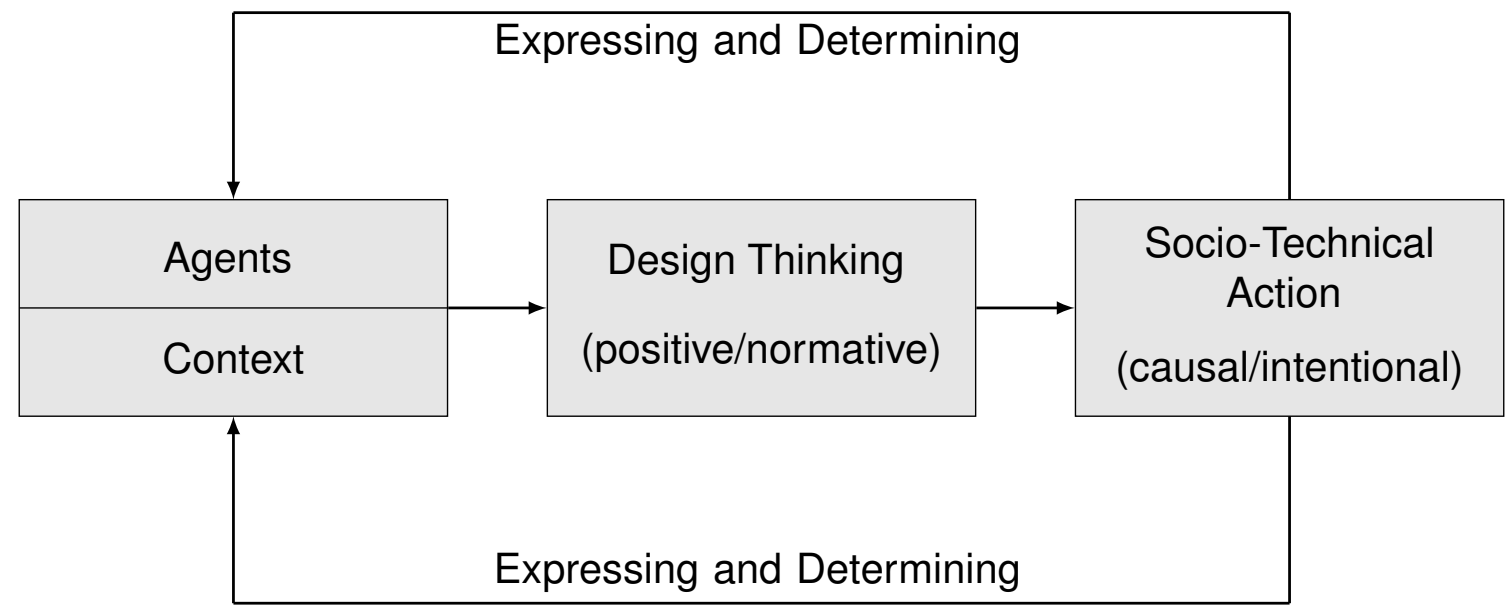

Figure 5: A representation of design process, as the movement of intentional agents embedded in a set of structures via thinking towards socio-technical action. Action is at the same time a manifestation (expression) of agents and structures, as well as what derives the development of agents and structures.

In Figure 5, we propose a representation of design process from a dialectic point of view. To better clarify this model we finish this section by explaining the concepts involved in our schema.

\subsubsection{Main Concepts: Design Thinking \& Socio-Technical Action}

First, we would point to the loop-like shape of the diagram capturing the self-reflexivity of design process. The socio-technical action is concurrently the way in which agents and structures become manifest, as well as the way in which agents and structures are developed and changed. Socio-technical actions, such as use of tools and objects, scientific research, or governance and administration are rationalized by design thinking. Intersubjective inquiry, reasoning, and disputations constitute design thinking. Such thinking is often regarded as positive (descriptive on matters of fact) or normative (on matters of value and judgments). John Searle has shown that positive and normative thought are not mutually exclusive $\mathrm{i}^{30}$. He demonstrates that factual statements concerning human beings, despite their reference to what is, by definition contain statements about what should be. We regard this as another warrant for regarding the objective and subjective categories 
interactive and co-constitutive, in general, and in design. Thus, returning to our initial research questions, we conclude that engineering and design are political in nature as they involves decision making and actions that shape individuals and the environment they live in. We regard this conception in agreement with Tony Fry's notion of design as politics ${ }^{31}$ where he, too, urges for an ontological and self-reflexive approach in design, to address grand and pressing challenges facing modern technological societies.

\subsubsection{Implications for Engineering Education}

Here we highlight some of the pedagogical potentials of a design methodology belonging to the third category. First and foremost our conceptualization provides a tool for promotion of metacognitive learning ${ }^{32}$ in engineering design. Metacognition is often explicated along two dimensions. First, it entails knowledge of cognition, i.e., what one knows about cognition in general, and about one's own cognitive processes. Second, metacognition entails regulation of cognition ${ }^{\sqrt{33}}$ referring to activities such as planning, monitoring, and evaluating that help control one's learning 33 . Substantial evidence exists to support the positive role that regulation of cognition plays in enhancing learning achievements. The philosophy and the representation of design presented in Figure 5 can be used to map each step in regulation of cognition to the elements of the design process. For example, planning is the first step of the regulation in which the following questions can help orient the learner $\frac{33}{}$ :

1. What is the nature of the task?

2. What is my goal?

3. What kind of information and resources do I need?

In addressing the first question, students can chart design tasks such as problem framing, model development, simulations, and other decision making activities according to the category of positive/normative design thinking. For the second questions, when identifying goals, students are primarily concerned with socio-technical action, i.e., enacting (or nurturing) technical and social skills to design an artifact that affords its users a specific set of socio-technical actions. And finally, information and resources are concerned with the nexus of structure/agents. As the learning activity proceeds, monitoring and evaluating steps can be also infused with similar questions enabling students to engage with metacognition of design. We are presently developing this approach for implementation in educational settings and will report the findings in an ensuing publication.

\section{Conclusion}

The overwhelming impact of technology on social and individual life has been a central theme in philosophy of technology, and science and technology studies. Design studies too ${ }^{34}$ has amassed a growing body of scholarly work focused on manifold complexities of design and its role for social change. This paper, in part, seeks to engage in a generative dialogue across multiple perspectives in order to show new research avenues, and to contribute towards the development of practical tools, frameworks, and insights for designers and engineers. 
This paper examines the notion of logic and rationality in a number of established design methodologies. It also covers less explored methodologies and their potential for future development and application. The enormity and unprecedented character of crises and challenges facing our civil society, in particular environmental crises, and ever growing interface of society and technology, call for fundamental and critical evaluation of these issues.

Our study is motivated by two fundamental questions:

1. how are the individual factors (e.g., cognitive models and representations used by designers) and the social factors (e.g., legal and institutional structures, and historically accumulated forms of cultural and material capital) to be used for epistemic explanations of the design practice?

2. how can the relationship between objective and structural categories versus the subjective and intentional categories be resolved in explaining the engineering design?

We do not expect such long-standing and philosophically motivated questions to be resolved expeditiously. But, we regard the insights provided in posing these questions to be directly relevant to engineering education. For example, dominance of positivistic (essentialist) attitudes and consequently a well-documented culture of depoliticization ${ }^{35}$ and ideologies of individualism and meritocracy directly shape what engineers count or discount in problem solving and design. To nurture self-awareness, self-reflection, and a critical attitude towards everything, including epistemic and often implicit cognitive status quo of engineering profession, it is crucial to promote philosophical engagement with fundamental questions motivating this paper.

Although this paper is not exhaustively reviewing the literature, we justify our tentative taxonomy on theoretical grounds. The proposed schema can be further refined. This will entail a conceptual and analytic development that evolves in tandem with empirical work on existing practices of engineering design both in educational and professional settings. The authors are currently analyzing a data set on design review conversations ${ }^{24 \mid 25}$ and intend to further expand the formal dialectic theory of Rescher ${ }^{[5]}$ that is briefly reviewed in this paper.

\section{Acknowledgement}

The authors want to acknowledge Professor Robin Adams for her input and advice to this project.

\section{References}

[1] L. Winner, "Do artifacts have politics?," Daedalus, vol. 109, no. 1, pp. 121-136, 1980.

[2] P. Kroes and A. Meijers, "The dual nature of technical artefacts," Studies in History and Philosophy of Science, vol. 37, pp. 1-4, 032006. 
[3] A. Feenberg, "Marcuse or habermas: Two critiques of technology," Inquiry, vol. 39, no. 1, pp. 45-70, 1996.

[4] A. Akera, "Constructing a representation for an ecology of knowledge: Methodological advances in the integration of knowledge and its various contexts," Social Studies of Science, vol. 37, no. 3, pp. 413-441, 2007.

[5] N. Rescher, Dialectics: A Controversy-Oriented Approach to the Theory of Knowledge. State University of New York Press, 1977.

[6] W. V. Quine, Elementary Logic. Harvard University Press, 2001.

[7] I. Kant, Logic. Dover books on Western philosophy, Dover, 1988.

[8] L. March, "The logic of design and the question of value," The Architecture of Form, 1976.

[9] C. S. Peirce, "Deduction, Induction, and Hypothesis," Popular Science Monthly, vol. 13, pp. 470-482, 1878. From the Commens Bibliography.

[10] N. Cross, Developments in design methodology. Wiley, 1984.

[11] K. Dorst, “The core of 'design thinking' and its application," Design Studies, vol. 32, no. 6, pp. 521 - 532, 2011. Interpreting Design Thinking.

[12] J. Kolko, "Abductive thinking and sensemaking: The drivers of design synthesis," Design Issues, vol. 26, pp. 15$28,122010$.

[13] C. Arnsperger and Y. Varoufakis, "What Is Neoclassical Economics? The three axioms responsible for its theoretical oeuvre, practical irrelevance and, thus, discursive power," Panoeconomicus, vol. 53, pp. 5-18, March 2006.

[14] Y. Varoufakis, Economic indeterminacy: a personal encounter with the economists' peculiar nemesis. Routledge London; New York, 2014.

[15] G. A. Hazelrigg, Fundamentals of decision making for engineering design and systems engineering. NEILS CORP, 2012.

[16] V. Lowndes, D. Marsh, and G. Stoker, Theory and Methods in Political Science. Political Analysis, Macmillan Education UK, 2017.

[17] D. Green and I. Shapiro, Pathologies of Rational Choice Theory: A Critique of Applications in Political Science. Pathologies of Rational Choice Theory: A Critique of Applications in Political Science, Yale University Press, 1996.

[18] O. E. WILLIAMSON, "Transaction Cost Economics and Organization Theory," Industrial and Corporate Change, vol. 2, pp. 107-156, 051993.

[19] R. Yager and L. Zadeh, Fuzzy sets, neural networks, and soft computing. VNR computer library, Van Nostrand Reinhold, 1994.

[20] D. Walton, The New Dialectic: Conversational Contexts of Argument. The New Dialectic: Conversational Contexts of Argument, University of Toronto Press, 1998.

[21] S. Jarupathirun and F. Zahedi, "Dialectic decision support systems: System design and empirical evaluation," Decision Support Systems, vol. 43, no. 4, pp. 1553 - 1570, 2007. Special Issue Clusters.

[22] C. M. Gray, "Informal peer critique and the negotiation of habitus in a design studio," Art, Design \& Communication in Higher Education, vol. 12, no. 2, pp. 195-209, 2013.

[23] W. M. Stroup, N. M. Ares, and A. C. Hurford, "A dialectic analysis of generativity: Issues of network-supported design in mathematics and science," Mathematical Thinking and Learning, vol. 7, no. 3, pp. 181-206, 2005.

[24] R. S. Adams and J. Siddiqui, "Purdue dtrs-design review conversations database," West Lafayette, IN USA, 2013. 
[25] R. S. Adams and J. A. Siddiqui, Analyzing design review conversations. Purdue University Press, 2015.

[26] T. Adorno and C. Ziermann, An Introduction to Dialectics. Wiley, 2017.

[27] T. Lawson, "Comparing conceptions of social ontology: Emergent social entities and/or institutional facts?," Journal for the Theory of Social Behaviour, vol. 46, no. 4, pp. 359-399, 2016.

[28] C. Hay, Political Analysis: A Critical Introduction. Political Analysis, Palgrave Macmillan, 2002.

[29] D. J. Singer, "The level-of-analysis problem in international relations," World Politics, vol. 14, no. 1, pp. 77-92, 1961.

[30] J. R. Searle, How to derive 'ought' from 'is', pp. 120-134. London: Palgrave Macmillan UK, 1969.

[31] F. Tony, Design as Politics. New York: Berg, 2011.

[32] L. Anderson, D. Krathwohl, and B. Bloom, A taxonomy for learning, teaching, and assessing: a revision of Bloom's taxonomy of educational objectives. Longman, 2001.

[33] G. Schraw, "Promoting general metacognitive awareness," Instructional Science, vol. 26, pp. 113-125, Mar 1998.

[34] N. Cross, "Design research: A disciplined conversation," Design Issues, vol. 15, no. 2, pp. 5-10, 1999.

[35] E. A. Cech, The (Mis)Framing of Social Justice: Why Ideologies of Depoliticization and Meritocracy Hinder Engineers' Ability to Think About Social Injustices, pp. 67-84. Dordrecht: Springer Netherlands, 2013. 